\title{
Changing rate of serious infections in biologic-exposed rheumatoid arthritis patients. Data from South American registries BIOBADABRASIL and BIOBADASAR
}

Roberto Ranza ${ }^{1,2}$ (1) $\cdot$ Maria Celina de la Vega ${ }^{3}$ leda Maria Magalhães Laurindo ${ }^{4}$. Marìa Gimena Gómez ${ }^{5}$. David Cezar Titton ${ }^{6}$. Adriana Maria Kakehasi ${ }^{7}$ - Alejandro Brigante ${ }^{5}$ - Alejandro Benitez ${ }^{3}$. Aline Ranzolin ${ }^{8}$. Amelia Granel $^{9}$ - Ana María Cappuccio ${ }^{10}$. Ana Quinteros ${ }^{11}$. André Luiz Shinji Hayata ${ }^{12}$. Andrea Smichowski ${ }^{13}$. Ângela Luzia Branco P. Duarte ${ }^{14}$. Barbara Stadler Kahlow ${ }^{15}$. Carolina Sánchez Andia ${ }^{16}$. Claiton Viegas Brenol ${ }^{17}$. Edson Velozo ${ }^{18}$. Eduardo Mussano ${ }^{19}$ • Enrique R. Soriano ${ }^{20}$. Georges Basile Christopoulos ${ }^{21} \cdot$ Geraldo da Rocha Castelar Pinheiro $^{22}$ - Gláucio Ricardo Werner de Castro ${ }^{23}$. Gustavo Casado ${ }^{13}$. Hellen Mary da Silveira Carvalho ${ }^{24}$. Ida Elena Exeni ${ }^{25}$. Inês Guimarães da Silveira ${ }^{26}$. Ingrid Petkovic ${ }^{27}$ • Ivanio Alves Pereira ${ }^{28}$ • Izaias Pereira da Costa ${ }^{29}$. Javier Eduardo Rosa ${ }^{22}$. José Roberto Silva Miranda ${ }^{30}$. Julio Cesar Bertacini de Moraes ${ }^{31}$ - Manoel Barros Bertolo ${ }^{32}$. Manuel Buhl ${ }^{33}$. Maria Alícia Lázaro ${ }^{34}$. Maria de Fátima Lobato C. da Sauma ${ }^{35}$. Marcelo de Medeiros Pinheiro ${ }^{36}$. Monica Díaz ${ }^{37}$. Mônica Valéria Siqueira Santana de Vechi ${ }^{38}$. Osvaldo Luis Cerda ${ }^{39}$. Pablo Astesana ${ }^{40}$. Pablo Finucci Curi ${ }^{41}$ • Paulo Louzada-Jr ${ }^{42}$. Reginaldo Botelho Teodoro ${ }^{43}$. Roberto Acayaba Toledo ${ }^{44}$.

Sílvia Papasidero ${ }^{45}$. Valeria Valim ${ }^{46}$. Vander Fernandes ${ }^{47}$. Veronica Saurit ${ }^{48}$. Washington Alves Bianchi ${ }^{49} \cdot$ on behalf of the BIOBADABRASIL study group, Sociedade Brasileira de Reumatologia and of the BIOBADASAR study group, Sociedad Argentina de Reumatologia • Rogério de Melo Costa Pinto ${ }^{50}$ - Miguel Angel Descalzo ${ }^{51}$ • Juan Jesus Gomez-Reino ${ }^{52}$

Received: 6 January 2019 / Revised: 2 March 2019 / Accepted: 13 March 2019 /Published online: 17 April 2019

(C) The Author(s) 2019

\begin{abstract} data from South American countries with different backgrounds and health-care systems but similar registries. years and adjusted IR ratio (aIRR) were estimated for bDMARDs and csDMARDs. IR for bDMARDs decreased over time in both registries, dropping from 36.59 (28.41-47.12) in 2012 to 7.27 (4.79-11.05) in 2016. toward a reduction was observed in the last years.

Key Points

- New comprehensive data on biologic drugs safety from international collaboration in South America.

- First proposal for national registries data merging in South America.

- Serious infections remain a major concern in RA patients treated with biologics.

- A significant reduction of serious infections in RA patients exposed to biologics was observed over a 7 years period.
\end{abstract}

Objective Most reports on serious infections (SI) in rheumatoid arthritis (RA) patients treated with biological disease-modifying antirheumatic drugs (bDMARDs) are from the USA and Western Europe. Data from other regions are largely missing. We report

Methods We merged 2010-2016 data from two registries, BIOBADABRASIL (Brazil) and BIOBADASAR (Argentina), which share the same protocol, online platform and data monitoring process. Patients with active RA were included when they began the first bDMARD or a conventional synthetic DMARD (csDMARD, control group). The SI incidence rate (IR) per 1000 patient/

Results Data were analysed for 3717 RA patients with an exposure of 13,380 patient/years. The 2591 patients treated with bDMARDs (64\% tumour necrosis factor- $\alpha$ inhibitors (TNFi)) had a follow-up of 9300 years, and the 1126 treated with csDMARDs had an exposure of 4081 patient/years. The SI IR was 30.54 (CI 27.18-34.30) for all bDMARDs and 5.15 (CI 3.36-7.89) for csDMARDs. The aIRR between the two groups was $2.03([1.05,3.9] p=0.034)$ for the first 6 months of treatment but subsequently increased to $8.26([4.32,15.76] p<0.001)$. The SI

Conclusion While SI remains a major concern in South American patients with RA treated with bDMARDs, a favourable trend

Roberto Ranza

robertoranza@gmail.com

Extended author information available on the last page of the article 
Keywords Biological agents $\cdot$ Registries $\cdot$ Rheumatoid arthritis $\cdot$ Safety $\cdot$ Serious infections

\section{Introduction}

Infections are the most frequent and concerning serious adverse events related to rheumatoid arthritis (RA) treatment with biological disease-modifying antirheumatic drugs (bDMARDs) [1]. Substantial regional differences have been observed, especially when epidemiology of infections and sociodemographic profiles of populations are considered [2]. Registries increase our knowledge of drug safety profiles in real-life settings and help to provide useful recommendations for clinical practice. In 2009, the BIOBADAMERICA registry project, open to all South and Central America countries, was established. It focused on safety monitoring of bDMARDs in rheumatic diseases and shared the same platform used by the previously established BIOBADASER registry [3]. The Brazilian (BIOBADABRASIL) and Argentinian (BIOBADASAR) registries are owned and sponsored by the Brazilian Society of Rheumatology (SBR) and the Argentinian Society of Rheumatology (SAR), respectively. This grants independence, availability to all interested investigators, clear methodological guidelines and consistent training programs $[4,5]$. Merging data of different registries is common but hampered by clear differences in the platform and definitions worldwide [6-8]. The common platform and methodology in BIOBADAMERICA minimize this challenge [3]. The purpose of this study was to present data on serious infections (SI) and the trends over time in patients with RA treated with bDMARDs in two South American countries based on data collected in analogous registries.

\section{Methods}

BIOBADABRASIL and BIOBADASAR are observational, prospective, time-unlimited, multicentre registries that share the same virtual platform. Patients are included from 32 rheumatology units in Brazil and 49 in Argentina, covering almost all of the regions in these two countries. Their identical online protocols consist of three domains. Briefly, the first domain covers demographics, disease characteristics, comorbidities and infectious disease screening data. The second covers treatment information like prescribed drug, treatment duration and comedications. The third covers adverse events (AE) and their outcomes. Protocols are available at https://biobadaser.ser.es/ biobadamerica/. Since registries are non-compulsory, principal investigators are responsible for the decision to include patients. The following inclusion criteria were required: any rheumatic disease starting a treatment with the first bDMARD (up to 3 months) or with a conventional synthetic disease-modifying anti-rheumatic drug
(csDMARD, up to 3 months) with no previous exposure to bDMARDs (internal control group). Data were updated in the case of treatment modifications or when AE occurs. All AE were classified according to the Medical Dictionary for Regulatory Activities (MedDRA). Data were continuously monitored online and in-loco at all centres by trained monitors. The registry data were compared every year with the medical records of a random sample of $20 \%$ of included patients. Data were anonymized before analysis. The ethical committee of each centre approved this study that have been performed in accordance with the ethical standards laid down in the 1964 declaration of Helsinki and its later amendments. All patients signed an informed consent document.

\section{Study groups and definitions}

BIOBADABRASIL and BIOBADASAR data were combined for the purpose of this study. Patients entered from January 1, 2010, to December 31, 2016 were included. Only RA patients were selected for this analysis. The biological drugs were divided into the following two groups: tumour necrosis factor- $\alpha$ inhibitors (TNFi: Adalimumab, Certolizumab, Etanercept, Golimumab and Infliximab) and non-TNFi (abatacept, rituximab and tocilizumab). Patients exposed to Tofacitinib were included in the non-TNFi group due to the mechanism of action and because it is indicated after the csDMARDs failure like a bDMARD.

According to the common registry standardized protocol, a serious infectious $\mathrm{AE}$ was defined as a clinical event, with infectious characteristics, that can cause death or is considered life-threatening; that implies inpatient treatment, admittance, or prolongation of hospitalization; or that results in persistent or significant disability/incapacity or a congenital anomaly/ birth defect.

\section{Statistical analysis}

A comparative descriptive statistical analysis was performed with merged data from both registries, between RA patients treated with bDMARDs and csDMARDs. Only patients with complete data were selected. Exposure time was considered from the start of drug intake to the date of last administration plus twice the drug half-life, even when a new drug was initiated immediately, or censorship (last recorded visit, drug withdrawal, patient death, or database download, whichever occurred first). Continuous variables are expressed as mean and standard deviation (SD), and categorical variables are expressed as absolute and percentage values. Student's $t$ and chi-square tests were used to compare variables between groups, especially in those with and without SI; a crude odds 
ratio (OR) and adjusted odds ratio (aOR) were estimated using logistic regression analysis. The SI-related AE incidence rate (IR) per 1000 patient years with $95 \% \mathrm{CI}$ and the incidence rate ratio (IRR) between groups were estimated using a Poisson model. The adjusted IRR (aIRR) was calculated using confounding factors at baseline, such as age, disease duration, disease activity, methotrexate (MTX) use and corticosteroid use. The level of significance was set at 0.05 .

\section{Results}

\section{Registry populations and treatments}

Data were obtained and analysed for 3717 RA patients and 4986 treatments covering a total of 13,380 patient years. The main characteristics of the registry patients are outlined in Table 1. Patients in BIOBADABRASIL were younger, had slightly higher DAS28 scores and were more likely to be smokers and to have been exposed to two or more biologics. Table 2 shows merged data for the two registries according to treatment group. Among bDMARDs, follow-up times were longer for TNFi than for non-TNFi. There were statistically significant differences in baseline characteristics between patients in bDMARDs and csDMARDs groups. The former were older and had longer disease durations, higher DAS28 scores and concomitant corticosteroid use. Subsequent analyses were therefore adjusted for these parameters, when appropriate.

\section{Serious infection rates for bDMARDs and csDMARDs}

A total of 284 SI events were reported for all bDMARDs group in a follow-up time of 9300 years. The IRs per 1000 patient years values were 30.54 (CI 27.18-34.30) for all bDMARDs and 31.33 (CI 27.21-36.06) for TNFi and 28.97 (CI 23.56-35.61) for non-TNFi. As for csDMARDs, $21 \mathrm{SI}$ were registered during a follow-up time of $4081 \mathrm{p} / \mathrm{y}$, resulting in an IR of 5.15 per 1000 patient years (CI 3.36-7.89) with a crude IRR of 5.93 [3.81,9.24] vs all bDMARDs and 5.17 $[3.29,8.15]$ when adjusted for confounding factors. Thirteen cases of tuberculosis were registered in bDMARDs group, resulting in an IR of 1.4 per 1000 patient years $(0.81-2.41)$ for all bDMARDs, $1.45(0.76-2.79)$ for TNFi and $1.29(0.48$ 3.43) for non-TNFi. The incidence was higher in Brazil, where there were eight cases (IR $1.46(0.73-2.92))$ than in Argentina, with five cases (IR $0.63(0.26-1.52)$ ). No such events were observed in either control group. Thirteen cases of Herpes Zoster were registered as serious, resulting in IR values of $1.4(0.81-2.41)$ for all bDMARDs, $1.29(0.65-2.58)$ for TNFi and $1.61(0.67-3.87)$ for non-TNFi. Notably, no cases of Hansen's disease (leprosy) were reported as an SI in either registry.

\section{Risk factors for serious infections}

Table 3 shows the analysis of patient and treatment characteristics associated with SI. Exposure to more than one bDMARD, corticosteroid use, smoking and renal failure were
Table 1 General overview of the rheumatoid arthritis patients included in the analysis, including details about BIOBADABRASIL and BIOBADASAR populations

\begin{tabular}{llll}
\hline & Total & BIOBADABRASIL & BIOBADASAR \\
\hline Patients & 3717 & 1499 & 2218 \\
Treatments & 4986 & 2134 & 2852 \\
Patient (years) & 13,380 & 5454 & 7926 \\
Patients on all biologics & 2591 & 1185 & 1406 \\
Patients on TNFi $^{\mathrm{a}}$ & $1897(73)$ & $936(79)$ & $961(68)$ \\
Patients exposed to two or more biologics $^{\mathrm{a}}$ & $814(31)$ & $419(35)$ & $395(28)$ \\
Patients on csDMARDs (control group) & 1126 & 314 & 812 \\
Females $^{\mathrm{a}}$ & $3158(85)$ & $1291(86)$ & $1867(84)$ \\
Age at baseline (years) $^{\mathrm{b}}$ & $52.4(13.1)$ & $50.9(12.3)$ & $53.4(13.5)$ \\
Disease duration at baseline (years) $^{\mathrm{b}}$ & $8.4(8.5)$ & $8.7(8.2)$ & $8.1(8.7)$ \\
Follow-up time (years) $^{\mathrm{b}}$ & $2.9(2.1)$ & $2.8(2.1)$ & $3.0(2.0)$ \\
DAS28 at baseline $^{\mathrm{b}}$ & $4.9(2.7)$ & $5.2(2.1)$ & $4.8(3.1)$ \\
Seropositivity, RF and/or aCCP $^{\mathrm{a}}$ & $3425(92)$ & $1300(87)$ & $2125(96)$ \\
Smokers $^{\mathrm{a}}$ & $414(11)$ & $207(14)$ & $207(9)$ \\
Diabetes mellitus $^{\mathrm{a}}$ & $308(8)$ & $170(11)$ & $138(6)$ \\
\hline
\end{tabular}

$D A S$ Disease Activity Score, $R F$ rheumatoid factor, $a C C P$ anti-cyclic citrullinated peptide

${ }^{\text {a }}$ Categorical variables are presented as $N(\%)$

${ }^{\mathrm{b}}$ Continuous variables as mean $\pm \mathrm{SD}$ 
Table 2 Descriptive analysis of all 3717 rheumatoid arthritis patients according to treatment group

\begin{tabular}{|c|c|c|c|c|c|}
\hline & All bDMARDs & TNFi & Non-TNFi & csDMARDs & $p$ value* \\
\hline Patients $N(\%$ of 3717$)$ & $2591(70 \%)$ & $1897(51 \%)$ & $694(19 \%)$ & $1126(30 \%)$ & \\
\hline Treatments & 3784 & 2484 & 1300 & 1202 & \\
\hline Patient (years) & 9300 & 6323 & 2977 & 4081 & \\
\hline Females, $N(\%)$ & $2205(85 \%)$ & $1618(85 \%)$ & $587(85 \%)$ & $953(85 \%)$ & 0.715 \\
\hline Age at baseline (years, mean $\pm \mathrm{SD}$ ) & $52.8(12.8)$ & $52.4(12.8)$ & $53.9(12.9)$ & $51.5(13.7)$ & 0.0037 \\
\hline Disease duration at baseline (years, mean $\pm \mathrm{SD}$ ) & $10.1(8.5)$ & $9.9(8.2)$ & $10.7(9.0)$ & $4.3(7.2)$ & $<0.001$ \\
\hline Follow-up time (years, mean $\pm \mathrm{SD}$ ) & $2.7(2)$ & $2.8(2)$ & $2.6(2)$ & $3.5(2.1)$ & $<0.001$ \\
\hline DAS28 at baseline (mean \pm SD) & $5.1(2.3)$ & $5.1(1.7)$ & $5.2(3.3)$ & $4.7(3.6)$ & $<0.001$ \\
\hline Seropositivity, RF and/or aCCP, $N(\%)$ & $2386(92)$ & $1722(91)$ & $664(96)$ & $1039(92)$ & 0.847 \\
\hline Methotrexate and/or leflunomide & $2124(82)$ & $1606(85)$ & $518(75)$ & $1013(90)$ & $<0.001$ \\
\hline Corticosteroids at baseline & $1513(58)$ & $1137(60)$ & $376(54)$ & $594(53)$ & 0.001 \\
\hline Smoker, $N(\%)$ & $296(11)$ & $207(11)$ & $89(13)$ & $118(10)$ & 0.741 \\
\hline Diabetes Mellitus, $N(\%)$ & $225(9)$ & $163(9)$ & $62(9)$ & $83(7)$ & 0.21 \\
\hline
\end{tabular}

$D A S$ Disease Activity Score, $R F$ rheumatoid factor, $a C C P$ anti-cyclic citrullinated peptide

* $p$ value for all bDMARDs vs csDMARDs

statistically related to SI even after adjustment for age, disease duration and activity, and MTX use at baseline. Interestingly, mean DAS28 scores were inversely and significantly related with SI.

\section{Changes over time in the incidence of serious infections}

The IR of SI was higher during the first 6 months of treatment than in subsequent months. In Table 4, IR values are shown for the treatment groups with crude and aIRR values for the comparison between csDMARDs and bDMARDs. The reduction of IR over time was more pronounced for csDMARDs than for bDMARDs, and the aIRR for the two groups increased from 2.03 [1.05, 3.90] during the first 6 months to $8.26[4.32,15.76]$ in the later study period. When the two bDMARDs groups were compared, the SI IR was definitely higher for non-TNFi in the first 6 months, and it sharply dropped during the subsequent treatment period.

A trend toward a reduction in SI IR over time was noted. Figure 1 shows the annual IR from 2010 to 2016. The trend was the same in both registries when data were analysed separately and reflected the same general tendency for all kinds of serious $\mathrm{AE}$, not only infectious, which were reduced from 57.97 (38.86-86.49) per 1000 patient years in 2010 to $16.86(12.81-22.18)$ in 2016 . The disease duration was stable over time for newly included patients (between 8.1 (SD 8.1) and 8.6 (SD 8.4) years).

\section{Serious infections responsible for drug withdrawal or death}

After a mean time of 2.45 (SD 1.91) years, $44.7 \%$ of bDMARD treatments were stopped. Serious side effects were responsible for $25 \%$ of bDMARDs interruptions. SI were responsible for withdrawal in $11.1 \%$ of bDMARDs cases, $11.6 \%$ of TNFi and $10.2 \%$ of non-TNFi. The main cause of bDMARDs stoppage was a lack or loss of effectiveness $(44 \%)$.

Sixteen deaths related to SI were registered. Of these, 15 occurred in the bDMARDs group, and 1 occurred in the control group, resulting in IR values of $1.29(0.73-2.27)$ and 0.25 $(0.03-1.74)$ per 1000 patient years, respectively, and an IRR of $5.3(0.68-40.5)$.

\section{Discussion}

In this paper, we report data on SI in a large cohort of RA patients exposed to biological DMARDs in South America. Data from this area of the world are scarce, and this is the first time a multinational project has provided comprehensive information based on an extensive follow-up period covering more than 13,000 patient years. The method used to merge data from two national biological drug safety registries was based on a well-defined common methodological framework [3]. Descriptive analyses of patients from Brazil and Argentina showed some baseline differences that help to understand the starting point of this study. 
Table 3 Risk factors associated with serious infections in patients treated with bDMARDs

\begin{tabular}{|c|c|c|c|c|c|c|}
\hline & Without SI & With SI & OR (CI 95\%) & $p$ value* & $\mathrm{aOR}(95 \% \mathrm{CI})$ & $p$ value* \\
\hline Patients $(N)$ & 2400 & 191 & & & & \\
\hline Age at first bDMARD, baseline years, mean (SD) & $52.8(12.8)$ & $53.2(12.9)$ & $1.00(0.99-1.01)$ & 0.681 & $1.01(0.99-1.02)$ & 0.096 \\
\hline Female, $N(\%)$ & $2043(85)$ & $162(84.5)$ & $0.98(0.65-1.47)$ & 0.908 & $1.04(0.68-1.59)$ & 0.865 \\
\hline Disease duration, years, mean (SD) & $10(8.5)$ & $10.7(8.1)$ & $1.01(0.99-1.03)$ & 0.300 & & \\
\hline Exposed to $1 \mathrm{~b}$ DMARD, $N(\%)$ & $1691(70)$ & $86(45)$ & ref & $<0.001$ & ref & $<0.001$ \\
\hline Exposed to 2 or more bDMARDs, $N(\%)$ & $709(30)$ & $105(55)$ & $2.91(2.16-3.92)$ & & $2.98(2.19-4.05)$ & \\
\hline csDMARD concomitant use, $N(\%)$ & $2053(85.5)$ & $164(85.9)$ & $1.03(0.67-1.57)$ & 0.903 & & \\
\hline Corticosteroid concomitant use, $N(\%)$ & $1370(57)$ & $143(75)$ & $2.24(1.60-3.14)$ & $<0.001$ & $2.14(1.52-3.03)$ & $<0.001$ \\
\hline DAS28 at baseline, mean (SD) & $5.2(2.3)$ & $4.8(1.6)$ & $0.89(0.82-0.97)$ & 0.009 & $0.84(0.76-0.92)$ & $<0.001$ \\
\hline Smoker, $N(\%)$ & $262(11)$ & $34(18)$ & $1.75(1.18-2.58)$ & 0.008 & $1.58(1.05-2.38)$ & 0.028 \\
\hline Diabetes mellitus, $N(\%)$ & $204(8.5)$ & $21(11)$ & $1.34(0.82-2.13)$ & 0.246 & & \\
\hline Previous cancer, $N(\%)$ & $41(1.7)$ & $3(1.8)$ & $0.91(0.28-2.98)$ & 0.882 & & \\
\hline Pulmonary chronic disease, $N(\%)$ & $48(2)$ & $5(2.6)$ & $1.31(0.52-3.34)$ & 0.567 & & \\
\hline Renal failure, $N(\%)$ & $10(0.4)$ & $3(1.6)$ & $3.80(1.04-13-91)$ & 0.03 & & \\
\hline
\end{tabular}

$O R$ crude odds ratio, $a O R$ adjusted odds ratio

${ }^{*} p$ value for comparison between patients with and without incident serious infection

In the bDMARDs group, almost two-thirds of the followup years consisted of patients on TNFi. This reflected the marketing timeline for biological agents in South America. Most patients in the csDMARDs, our control group, were on MTX and/or LEF, with $10 \%$ on hydroxychloroquine, sulfasalazine, or azathioprine. Based on a previous analysis of BIOBADABRASIL data and South America treatment practices, we estimate that approximately one third of the csDMARDs group had been exposed to a combination of MTX and LEF during the follow-up period [9], in accordance with national guidelines (i.e., before a bDMARD is indicated, a csDMARDs combination should be tried) [10,11].

According to our data, SI remain a major concern in RA patients exposed to bDMARDs. The global IR (30.54 for 1000 patient years) was similar for TNFi and non-TNFi and comparable to that found in most other registries, including BIOBADASER (31 (28-34)) which adopts the same methodology $[12,13]$. The crude IRR vs csDMARDs was almost 6 . Even our overall aIRR of 5.17 was higher than that reported in most observational studies published in the last 10 years (the majority of which were below 2 and have ranged from 0.9 to 1.8) [1]. However, in some countries, the aIRR is clearly higher, including 2.4 (1.1-5.1) in Japan, 2.7 (1.1-6.3) in Colombia and 6.9 (3.1-15.4) in Greece, indicating the existence of regional differences [14-16]. These differences could be related to patient factors, such as comorbidities, steroid use and dosages, or to control group particularities. In our parallel csDMARDs group, the overall SI IR was as low as 5.15 for 1000 patient years but was 18.9 for the first 6 months of treatment. In this group of patients, Listing et al. reported an IR of 23, while Dixon et al. reported an IR of 41.4 for 1000 patient years $[17,18]$. Interestingly, while the IR of SI increased over time in the British Society for Rheumatology Biologics Register (BSRBR) csDMARDs patients, we found that it clearly decreased [19].

In South America, tuberculosis remains an endemic disease with an incidence of 41 (35-47)/100,000 in Brazil and 25 (2229)/100,000 in Argentina [20]. It was therefore expected a tuberculosis IR for all bDMARDs higher in Brazil (1.46/1000) than in Argentina (0.63), and the overall IR of 1.4/1000 found in this study reflects the background risk in our countries [21]. No such events were observed in our control group on csDMARDs. It is important to consider that only cases who met the definition for SI are included in this analysis. For that reason, the total number of cases of tuberculosis could actually have been higher. In a previous paper on tuberculosis in RA patients included in BIOBADABRASIL through 2013, the incidence was 2.87/ 1000 in the TNFi group, and 1 event was observed in the control group. That control patient was not included in the present analysis because the patient's condition was not classified as a SI [22]. Two cases of pulmonary tuberculosis were identified in the BIOBADASAR control group, but again, these were classified as not serious, and both achieved recovery [unpublished data]. Notwithstanding, in a single centre study performed in Brazil, the incidence of active tuberculosis in RA patients exposed to TNFi was lower than that in our study $(0.37 / 1000)$, suggesting that in large countries with endemic tuberculosis, regional differences need to be considered [23]. Another mycobacterial disease that is still endemic in various South America areas is Hansen disease [24]. Single case reports have suggested a possible association between hanseniasis and exposure to TNFi $[4,25]$. Interestingly, no cases of Hansen disease classified as a SI 
Table 4 Incidence rate of serious infections in the first 6 months and all subsequent months according to treatment group

\begin{tabular}{lll}
\hline & First 6 months & Subsequent months \\
\hline All bDMARDs & $47.91(38.74-59.26)$ & $26.44(23.01-30.38)$ \\
TNFi & $36.18(26.73-48.95)$ & $29.83(25.47-34.94)$ \\
Non-TNFi & $70.15(52.02-94.58)$ & $19.04(14.21-25.49)$ \\
First bDMARD & $21.94(13.99-34.4)$ & $19.03(15.56-23.27)$ \\
Subsequent bDMARD & $72.69(57.11-92.52)$ & $41.04(33.87-49.74)$ \\
csDMARDs & $18.9(10.47-34.13)$ & $2.86(1.54-5.31)$ \\
IRR:all bDMARDs vs csDMARDs & $2.54[1.35,4.75]^{*}$ & $9.25[4.90,17.46]^{* * *}$ \\
aIRR: all bDMARDsvs csDMARDs & $2.03[1.05,3.90]^{* *}$ & $8.26[4.32,15.76]^{* * *}$ \\
aIRR: TNFi vs csDMARDs & $1.77[0.88,3.58]^{\#}$ & $9.68[5.04,18.60]^{* * *}$ \\
aIRR: non-TNFi vs csDMARDs & $2.53[1.23,5.17]^{\# \#}$ & $5.06[2.44,10.48]^{* * *}$ \\
\hline
\end{tabular}

Values are shown as the incidence rate for 1000 patient/years (95\% confidence interval) $I R R$ incidence rate ratio, $I I R R$ adjusted incidence rate ratio

${ }^{*} p$ value $=0.004 ; * * p$ value $=0.034 ; * * * p$ value $<0.001 ;{ }^{\#} p$ value $<0.111 ;{ }^{\# \#} p$ value $<0.011$ have been reported in either registry. According to the literature, the absolute risk of a Herpes Zoster episode occurring in a patient treated with a TNFi is $11.9 / 1000$ patient years, and $4.9-20.9 \%$ of such episodes are classified as serious [26]. In our series, we found a crude IR of Zoster infections classified as serious of $1.29 / 1000$ patient years, which appears to be in agreement with previously reported data [24]. The IR was higher in the nonTNFi group (1.61) [27].

The SI IR was higher in the first 6 months for all treatments. These analyses confirm the observations reported in previous registry data of TNFi $[19,28-30]$. During this exposure period, the aIRR for all bDMARDs vs all csDMARDs was 2.03, which is similar [29] or lower than that observed in other cohorts $[19,28]$. Of note, the higher SI IR were reported in the non-TNFi group. In a recent paper from the BSRBR, rituximab and tocilizumab were associated with higher SI rates in unadjusted analysis, findings partly explicated by patient characteristics [31]. We agree with Rutheford and colleagues that this could reflect the usual prescription pattern for nonTNFi in clinical practice: in most cases, they are initiated after one or more TNFi and frequently with no wash out. In our database, the higher SI IR for a subsequent bDMARD than for a first bDMARD may indirectly support this interpretation. In the subsequent months, we observed a general reduction in SI IR, especially for csDMARDs with an aIRR increased to 8.26 vs all bDMARDs. There was also a substantial drop from 70.15 to 19.04 per $1000 \mathrm{p} / \mathrm{y}$ in the SI IR in the non-TNFi group. The principal explanation for why the SI IR reduced with treatment time could be that the patients who are more susceptible to serious adverse events are more likely to present a SI during the first months of exposure [32]. Our data did not allow us to investigate whether reducing corticosteroid use or improved function were contributing factors. We did not consider under-reporting after the initial months as a possible explanation. The patient follow-up strategy remained the same (visits every 3 months) over time. Furthermore, we considered only SI, which are less likely to be under-reported. Regardless of interpretation, results represent our clinical practices and offer a valid framework to support adequate patient monitoring strategies.

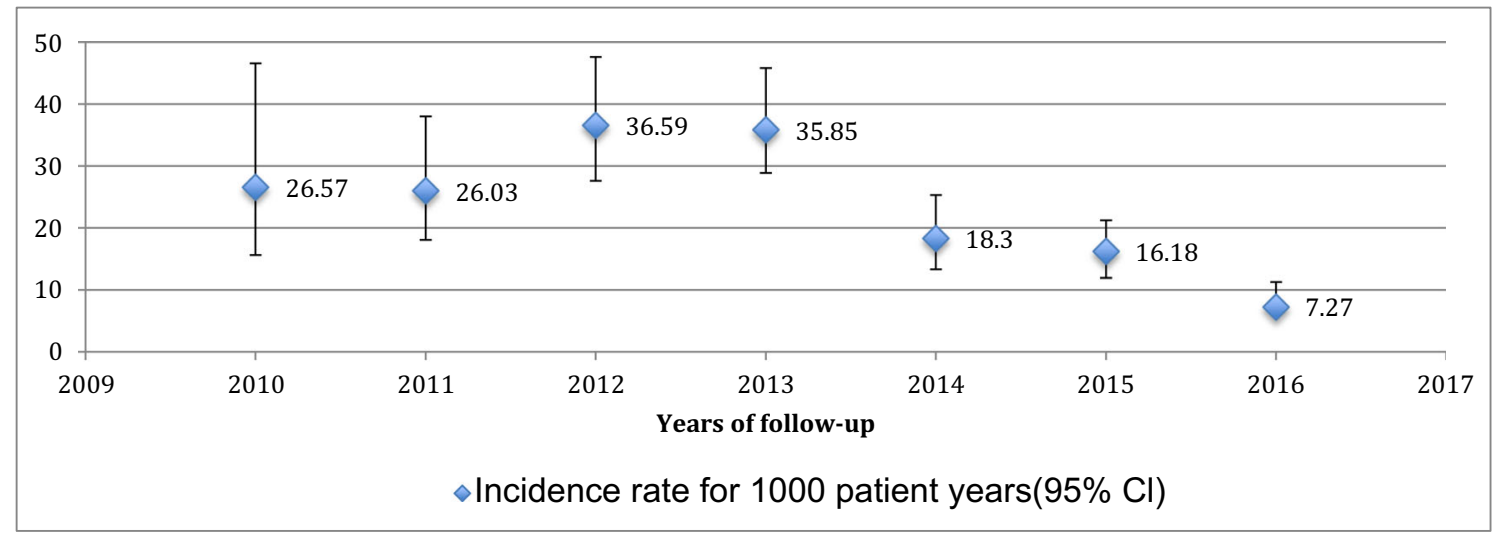

Fig. 1 Change over time in the incidence rate of serious infections in patients treated with bDMARDs 
From 2010 to 2016, there was a clear decline in the SI IR in the bDMARDs group in our registries, accompanying the IR for overall serious adverse events. Other registries have reported the same phenomenon. In the Swedish (Anti-rheumatic Therapies in Sweden) ARTIS registry, the relative risk of hospitalization for a SI for patients on a first TNFi reduced from 1.43 in the first year to 1.15 in the second and to 0.82 in subsequent years [33]. In the Japanese RA patients on biologics for long-term safety (REAL) registry, the crude IRR for SI in patients on TNFi was 0.5 between the 2008 and 2005 groups (aHR, $0.43(0.20-0.93))$ [34]. In a 2008 review of four registry databases, a trend for the risk of SI to decrease over time has been confirmed [35]. Multiple explanations are possible for this phenomenon. One is patient selection for bDMARDs, including the so-called "depletion of susceptibles" [19, 35], while increasing physician competence in identifying and treating infections and recognizing individual risk is another. A progressive increasing awareness about vaccination relevance might also have influenced SI incidence decrease. Registry-related factors, including the fact that fewer new patients are included over time, leading to progressively higher numbers of patient/years during follow-up with relatively fewer SI events, should also be considered. Because we now treat RA earlier in the course of the disease, the shorter disease duration in newly included bDMARDs patients over the years could be another factor that contributes to the observed drop in SI. However, in our series, the baseline disease duration was stable over time.

Among the elements associated with SI, exposure to more than one bDMARDs produced a higher aOR of almost 3 ( $p<$ $0.001)$. It was followed by corticosteroid use at baseline (2.14, $p<0.001)$ and smoking $(1.58, p=0.028)$. Data from the Danish DREAM registry confirmed that baseline corticosteroid use is a 5-year SI risk factor [34]. Interestingly, they also found that disease activity parameters, such as pain by visual analogue scale and tender joints by the 28-joint count, were associated with infection risk, while in our database, baseline DAS28 was inversely related with SI along the follow-up (aOR $0.84, p<0.001$ ) [36]. That could be due, at least in part, to a more accurate assessment and/or to a tighter control during the first months of the follow-up. An analysis of the Japanese REAL registry produced similar findings [14]. It is important to remember that RA and corticosteroid use have been identified as risk factors for SI independent of bDMARDs [37], and they have also been associated with the shorter survival of the first TNFi [38].

An SI resulted in the interruption of $11 \%$ of bDMARD treatments. SI was the cause of death in fivefold more bDMARDs than csDMARDs patients. This result is quite different from that reported in the German Rheumatoid Arthritis oBservation of BIologic Therapy (RABBIT) registry, in which patients on a bDMARD at the time of an SI were significantly less likely to develop sepsis or have a fatal outcome than were those on a csDMARD (OR 0.56) [39]. In a population study conducted in São Paulo State in Brazil, when RA was considered to be the underlying cause of a death, infections were the most frequently reported fatal events [40].

Our work has some relevant strengths. Our data are based on multinational large registry databases that use identical methodological frameworks. The consistency is guaranteed by a constant monitoring process, including in situ audits of patient records. This reduces the risk that serious AE will be underreported. Furthermore, the control group is internal and parallel, followed likewise by the bDMARDs group.

We understand that the main limitations of this study are those common to all non-compulsory registry cohorts with a possible selection bias of patients. One specific limitation of our database is the large amount of missing data on pathogens causative of SI, for this reason not presented in this paper. In addition, we have scarce information regarding socioeconomic level, co-morbidities and co-medications taken by patients. For instance, only baseline data were available for steroid and concomitant csDMARDs use. Information on dosage and adherence over time would allow better exploration of their potential influence on SI rates. Protocol data limitation was a conscientious choice in that we agreed with the BIOBADASER philosophy, which is to keep things simple to improve feasibility. This was mainly because a project goal was to involve as many investigators as possible, and investigator resources are frequently limited in our continental countries. These limitations will be reduced in the future because our registries are migrating to a new platform that will include more mandatory follow-up data.

\section{Conclusion}

In South America, SI remain a major burden in RA patients taking biologics, especially during the first 6 months of exposure. The trends we found over time were favourable in that they show a reduction in the frequency of such events over the last 7 years.

Acknowledgements The authors thank the Brazilian and Argentinian Societies of Rheumatology and their monitors for the organizational support and the intense data quality program. Our special thanks to registries investigators who were not included among the authors of this paper for their valuable contribution to the database.

Funding The registries BIOBADABRASIL and BIOBADASAR had the financial support of the respective national rheumatology society that are the only owners of the data.

Availability of data The datasets supporting the conclusions of this article are available through the Brazilian and Argentinian Societies of Rheumatology, who are the owners and have full control on the primary data, available for journal review. Information could not be public to avoid possible commercial use. 


\section{Compliance with ethical standards}

Competing interests All authors are members of the respective national rheumatological society. All authors declare to have no competing interests.

Ethics approval Ethics committees of the leading centres in Brazil and Argentina (Curitiba and Buenos Aires) approved the study. Each site obtained the approval of local ethics committee. All patients signed an informed consent prior to inclusion in the registries.

Open Access This article is distributed under the terms of the Creative Commons Attribution 4.0 International License (http:// creativecommons.org/licenses/by/4.0/), which permits unrestricted use, distribution, and reproduction in any medium, provided you give appropriate credit to the original author(s) and the source, provide a link to the Creative Commons license, and indicate if changes were made.

\section{References}

1. Ramiro S, Sepriano A, Chatzidionysiou K, Nam JL, Smolen JS, van der Haijde D et al (2017) Safety of synthetic and biological DMARDs: a systematic literature review informing the 2016 update of the EULAR recommendations for management of rheumatoid arthritis. Ann Rheum Dis 76(6):1101-1136

2. Dixon WG, Carmona L, Finckh A, Hetland ML, Kvien TK, Landewe R et al (2010) EULAR points to consider when establishing, analysing and reporting safety data of biologics registries in rheumatology. Ann Rheum Dis 69:1569-1602

3. Carmona L, de la Vega M, Ranza R, Casado G, Titton DC, Descalzo MA et al (2014) BIOBADASER, BIOBADAMERICA, and BIOBADADERM: safety registers sharing commonalities across diseases and countries. Clin Exp Rheumatol 32(Suppl. 85):S163-S167

4. Titton D, Silveira IG, Louzada JP, Hayata AL, Carvalho HMS, Ranza R et al (2011) Brazilian biologic registry: BiobadaBrasil implementation process and preliminary results. Rev Bras Reumatol 52:145-160

5. de la Vega M, Gomez G, Casado C, Battagliotti C, Exeni I, Gobbi C et al (2013) Tercer reporte de eventos adversos con tratamientos biológicos en Argentina. Informe de registro BIOBADASAR. Revista Argentina de Reumatologia 24(4):8-14

6. Zink A, Askling J, Dixon WG, Klareskog L, Silman AJ, Symmons DPM (2009) European biologicals registers: methodology, selected results and perspectives. Ann Rheum Dis 68:1240-1246

7. Curtis JR, Jain A, Askling J, Bridges SL Jr, Carmona L, Dixon W, Finckh A, Hyrich K, Greenberg JD, Kremer J, Listing J, Michaud K, Mikuls T, Shadick N, Solomon DH, Weinblatt ME, Wolfe F, Zink A (2010) A comparison of patients characteristics and outcomes in selected European and US rheumatoid arthritis registries. Semin Arthritis Rheum 40:2-14

8. Pease C, Pope JE, Truong D, Bombardier C, Widdifield J, Carter Thorne J et al (2011) Comparison of anti-TNF treatment initiation in rheumatoid arthritis databases demonstrates wide country variability in patients parameters at initiation of anti-TNF therapy. Semin Arthritis Rheum 41:81-89

9. Cecconi M, Ranza R, Titton D, Moraes JCB, Bertolo MB, Bianchi $\mathrm{W}$ et al (2018; online first) Incidence of infectious adverse events in patients with rheumatoid arthritis and spondyloarthritis on biologic drugs - data from the Brazilian registry for biologics monitoring. J Clin Rheumatol. https://doi.org/10.1097/RHU0000000000000935

10. da Mota LMH, Kakehasi AM, APM G, Pereira IA, Rezende-Fronza LS, Bertolo MB et al (2018) 2017 Recommendations of the
Brazilian Society of Rheumatology for the pharmacological treatment of Rheumatoid Arthritis. Advances in Rheumatology 58:2

11. Actualizacion de las guias de practica clinica en el tratamiento de la Artritis Reumatoidea - Grupo de estudio de artritis reumatoidea Sociedad Argentina de Reumatologia 2013. online: http://www. reumatologia.org.ar/docs/guias_sar_2013.pdf,

12. Ramiro S, Sepriano A, Chatzidionysiou K, Nam JL, Smolen JS, van der Haijde D et al. Safety of synthetic and biological DMARDs: a systematic literature review informing the 2016 update of the EULAR recommendations for management of rheumatoid arthritis Ann Rheum Dis Published Online First: March 15,2017. Online supplement - https://doi.org/10.1136/annrheumdis-2016-210708

13. Cobo-Ibáñez T, Descalzo MA, Loza-Santamaría E, Carmona L, Munoz-Fernandes S (2014) Serious infections in patients with rheumatoid arthritis and other immune-mediated connective tissue diseases exposed to anti-TNF or rituximab: data from the Spanish registry BIOBADASER 2.0. Rheumatol Int 34:953-961

14. Komano Y, Tanaka M, Nanki T, Koike R, Sakai R, Kameda H, Nakajima A, Saito K, Takeno M, Atsumi T, Tohma S, Ito S, Tamura N, Fujii T, Sawada T, Ida H, Hashiramoto A, Koike T, Ishigatsubo Y, Eguchi K, Tanaka Y, Takeuchi T, Miyasaka N, Harigai M, REAL Study Group (2011) Incidence and risk factors for serious infection in patients with rheumatoid arthritis treated with tumor necrosis factor inhibitors: a report from the Registry of Japanese Rheumatoid Arthritis Patients for Long-term Safety. J Rheumatol 38:1258-1264

15. Miranda JV, Peñaranda LFP, Grajales CM, Hernandez JDM, Padilla LMR, Franco CJV (2014) Infections in rheumatoid arthritis patients: biological therapy versus disease modifying anti-rheumatic drugs: one year follow-up. Rev Colomb Reumatol 21:27-34

16. Lampropoulos CE, Orfanos P, Bournia VK, Karatsourakis T, Mavragani C, Pikazis D, Manoussakis MN, Tzioufas AG, Moutsopoulos HM, Vlachoyiannopoulos PG (2015) Adverse events and infections in patients with rheumatoid arthritis treated with conventional drugs or biologic agents: a real world study. Clin Exp Rheumatol 33:216-224

17. Listing J, Strangfeld A, Kary S, Rau R, von Hinueber U, StoyanovaScholz M, Gromnica-Ihle E, Antoni C, Herzer P, Kekow J, Schneider M, Zink A (2005) Infections in patients with rheumatoid arthritis treated with biologic agents. Arthritis Rheum 52:3403-3412

18. Dixon WG, Watson K, Lunt M, Hyrich KL, British Society for Rheumatology Register Control Centre Consortium, Silman BJ et al (2006) Rates of serious infection, including site-specific and bacterial intracellular infection, in rheumatoid arthritis patients receiving antitumor necrosis factor therapy: results from the British Society for Rheumatology Biologics Register. Arthritis Rheum 54:2368-2376

19. Dixon WG, Symmons DPM, Lunt M, Watson KM, Hyrich KL (2007) British Society for Rheumatology Register Control Centre Consortium et al. Serious infection following anti-tumor necrosis factor - therapy in patients with rheumatoid arthritis. Arthritis Rheum 56:2896-2904

20. WHO Global Tuberculosis Report 2016. World Health Organization. WHO/HTM/TB/2016.13,

21. Ai JW, Zhang S, Ruan QL, Yu YQ, Zhang BY, Lin QH et al (2015) The risk of tuberculosis in patients with rheumatoid arthritis treated with tumor necrosis factor- $\alpha$ antagonist: a metaanalysis of both randomized controlled trials and registry/cohort studies. J Rheumatol 42:2229-2237

22. Yonekura CL, Oliveira RDR, Titton DC, Ranza R, Ranzolin A, Hayata AL et al (2017) Incidence of tuberculosis among patients with rheumatoid arthritis using TNF blockers in Brazil: data from the Brazilian Registry of Biological Therapies in Rheumatic Diseases (Registro Brasileiro de Monitoração de Terapias Biológicas - BIOBADABRASIL). Rev Bras Reumatol Engl Ed 57(Suppl 2):477-483 
23. Gomes CMF, Terreri MT, Moraes-Pinto MI, Barbosa C, Machado NP, Melo MR (2015) Incidence of active mycobacterial infections in Brazilian patients with chronic inflammatory arthritis and negative evaluation for latent tuberculosis infection at baseline - a longitudinal analysis after using TNFa blockers. Mem Inst Oswaldo Cruz 110:921-928

24. WHO Global leprosy update, 2015: time for action, accountability and inclusion. No 35, 2016, 91, 405-20,

25. Freitas DS, Machado N, Andrigueti FV, Ruis Neto ET, Pinheiro MM (2010) Hanseníase virchowiana associada ao uso de inibidor do fator de necrose tumoral $\alpha$ : relato de caso. Rev Bras Reumatol 50(3):333-339

26. Che H, Lukas C, Morel J, Combe B (2014) Risk of herpes/herpes zoster during anti-tumor necrosis factor therapy in patients with rheumatoid arthritis. Systematic review and meta-analysis. Joint Bone Spine 81:215-221

27. Curtis JR, Xie F, Yun H, Bernatsky S, Winthrop KL (2016) Realworld comparative risks of herpes virus infections in tofacitinib and biologic-treated patients with rheumatoid arthritis. Ann Rheum Dis 75:1843-1847

28. Curtis JR, Patkar N, Xie A, Martin C, Allison JJ, Saag M, Shatin D, Saag KG (2007) Risk of serious bacterial infections among rheumatoid arthritis patients exposed to tumor necrosis factor $\propto$ antagonists. Arthritis Rheum 56(4):1125-1133

29. Galloway JB, Hyrich KL, Mercer LK, Dixon WG, Fu B, Ustianowski AP, Watson KD, Lunt M, Symmons DP, BSRBR Control Centre Consortium, British Society for Rheumatology Biologics Register (2011) Anti-TNF therapy is associated with an increased risk of serious infection in patients with rheumatoid arthritis especially in the first 6 months of treatment: updated results from the British Society for Rheumatology Biologics Register with special emphasis on risk in the elderly. Rheumatology 50:124-131

30. Perez-Sola MJ, Torre-Cisneros J, Perez-Zafrilla B, Carmona L, Descalzo MA, Gomez-Reino JJ et al (2011) Infections in patients treated with tumor necrosis factor antagonists: incidence, etiology and mortality in the BIOBADASER registry. Med Clin 137(12): $533-540$

31. Rutheford AI, Subesinghe S, Hyrich KL, Galloway JB (2018) Serious infection across biologic-treated patients with rheumatoid arthritis: results from the British Society for Rheumatology Biologics Register for Rheumatoid Arthritis. Ann Rheum Dis 77: 905-910

32. Strangfeld A, Eveslage M, Schneider M, Bergerhausen HJ, Klopsch T, Zink A, Listing J (2011) Treatment benefit or survival of the fittest: what drives the time-dependent decrease in serious infection rates under TNF inhibition and what does this imply for the individual patient? Ann Rheum Dis 70:1914-1920

33. Askling J, Fored CM, Brandt L, Baecklund E, Bertilsson L, Felklius $\mathrm{N}$ et al (2007) Time-dependent increase in risk of hospitalisation with infection among Swedish RA patients treated with TNF antagonists. Ann Rheum Dis 66:1339-1344

34. Sakai R, Cho SK, Nanki T, Koike R, Watanabe K, Yamazaki H et al (2014) The risk of serious infection in patients with rheumatoid arthritis treated with tumor necrosis factor inhibitors decreased over time: a report from the registry of Japanese rheumatoid arthritis patients on biologics for long-term safety (REAL) database. Rheumatol Int 34:1729-1736

35. Askling J, Dixon W (2008) The safety of anti-tumour necrosis factor therapy in rheumatoid arthritis. Curr Opin Rheumatol 20: 138-144

36. Van Dartel SAA, Fransen J, Kievt W, Dutmer EAJ, Brus HLM, Houtman NM et al (2012) Predictors for the 5-year risk of serious infections in patients with rheumatoid arthritis treated with antitumour necrosis factor therapy: a cohort study in the Dutch Rheumatoid Arthritis Monitoring (DREAM) registry. Rheumatology 52:1052-1057

37. Doran MF, Crowson CS, Pond GR, O'Fallon WM, Gabriel SE (2002) Predictors of infection in rheumatoid arthritis. Arthritis Rheum 46:2294-2300

38. Fafá BP, Louzada-Junior P, Titton DC, Zandonade E, Ranza R, Laurindo I et al (2015) Drug survival and causes of discontinuation of the first anti-TNF in ankylosing spondylitis compared with rheumatoid arthritis: analysis from BIOBADABRASIL. Clin Rheumatol 34:921-927

39. Richter A, Listing J, Schneider M, Klopsch T, Kapelle A, Kaufmann J, Zink A, Strangfeld A (2016) Impact of treatment with biologic DMARDs on the risk of sepsis or mortality after serious infection in patients with rheumatoid arthritis. Ann Rheum Dis 75: $1667-1673$

40. Pinheiro FA, Souza DCC, Sato EI (2015) A study of multiple causes of death in rheumatoid arthritis. J Rheumatol 42:2221-2228

Publisher's note Springer Nature remains neutral with regard to jurisdictional claims in published maps and institutional affiliations.

\section{Affiliations}

Roberto Ranza ${ }^{1,2}$ (1) $\cdot$ Maria Celina de la Vega ${ }^{3} \cdot$ leda Maria Magalhães Laurindo ${ }^{4}$ Marìa Gimena Gómez ${ }^{5}$. David Cezar Titton ${ }^{6}$ - Adriana Maria Kakehasi ${ }^{7}$ - Alejandro Brigante ${ }^{5}$ - Alejandro Benitez ${ }^{3}$ - Aline Ranzolin ${ }^{8}$. Amelia Granel ${ }^{9}$ - Ana María Cappuccio ${ }^{10}$ - Ana Quinteros ${ }^{11}$ - André Luiz Shinji Hayata ${ }^{12}$ • Andrea Smichowski ${ }^{13}$. Ângela Luzia Branco P. Duarte ${ }^{14}$. Barbara Stadler Kahlow ${ }^{15}$. Carolina Sánchez Andia ${ }^{16}$. Claiton Viegas Brenol ${ }^{17}$. Edson Velozo ${ }^{18}$. Eduardo Mussano ${ }^{19}$. Enrique R. Soriano ${ }^{20}$. Georges Basile Christopoulos ${ }^{21}$. Geraldo da Rocha Castelar Pinheiro $^{22}$ • Gláucio Ricardo Werner de Castro ${ }^{23}$. Gustavo Casado ${ }^{13}$. Hellen Mary da Silveira Carvalho ${ }^{24}$. Ida Elena Exeni ${ }^{25}$ • Inês Guimarães da Silveira ${ }^{26}$ • Ingrid Petkovic ${ }^{27}$ • Ivanio Alves Pereira ${ }^{28}$ • Izaias Pereira da Costa ${ }^{29}$. Javier Eduardo Rosa ${ }^{22}$ • José Roberto Silva Miranda ${ }^{30}$. Julio Cesar Bertacini de Moraes ${ }^{31}$ • Manoel Barros Bertolo ${ }^{32}$. Manuel Buhl ${ }^{33}$ - Maria Alícia Lázaro ${ }^{34}$ - Maria de Fátima Lobato C. da Sauma ${ }^{35}$. Marcelo de Medeiros Pinheiro ${ }^{36}$. Monica Díaz ${ }^{37}$ • Mônica Valéria Siqueira Santana de Vechi ${ }^{38}$. Osvaldo Luis Cerda ${ }^{39}$ • Pablo Astesana ${ }^{40}$. Pablo Finucci Curi ${ }^{41}$ - Paulo Louzada-Jr ${ }^{42}$. Reginaldo Botelho Teodoro ${ }^{43}$. Roberto Acayaba Toledo ${ }^{44}$. Sílvia Papasidero ${ }^{45}$. Valeria Valim ${ }^{46}$. Vander Fernandes ${ }^{47}$. Veronica Saurit ${ }^{48}$. Washington Alves Bianchi ${ }^{49}$. Rogério de Melo Costa Pinto ${ }^{50}$. Miguel Angel Descalzo ${ }^{51}$. Juan Jesus Gomez-Reino ${ }^{52}$ 
Maria Celina de la Vega

mainadelavega.mdlv@gmail.com

Ieda Maria Magalhães Laurindo frlaurindo@uol.com.br

Marìa Gimena Gómez

gimenagmz@gmail.com

David Cezar Titton

mstitton@uol.com.br

\section{Adriana Maria Kakehasi}

amkakehasi@ufmg.br

Alejandro Brigante

alebrigante672@gmail.com

Alejandro Benitez

alebenitez3@gmail.com

Aline Ranzolin

aliranzolin@gmail.com

Amelia Granel

ameliagranel@gmail.com

Ana María Cappuccio

anamariacappuccio@gmail.com

Ana Quinteros

anaquinteros@yahoo.com

André Luiz Shinji Hayata

andre.hajata@gmail.com

Andrea Smichowski

andreasmichowski@hotmail.com

Ângela Luzia Branco P. Duarte angelabduarte@hotmail.com

Barbara Stadler Kahlow

bazinha_st@yahoo.com.br

Carolina Sánchez Andia

carolinasanchezandia@gmail.com

Claiton Viegas Brenol

claiton.brenol@gmail.com

Edson Velozo

ejvelozo@gmail.com

Eduardo Mussano

edemussano@yahoo.com.ar

Enrique R. Soriano

enrique.soriano@hospitalitaliano.org.ar

Georges Basile Christopoulos

georgesbasile@icloud.com

Geraldo da Rocha Castelar Pinheiro geraldo.castelar@gmail.com

Gláucio Ricardo Werner de Castro castrogrwc@gmail.com

Gustavo Casado

guscasado@hotmail.com
Hellen Mary da Silveira Carvalho sc2012hellen@gmail.com

Ida Elena Exeni

idaelenaexeni@gmail.com

Inês Guimarães da Silveira

ines.silveira@pucrs.br

Ingrid Petkovic

draspetkovic@yahoo.com.ar

Ivanio Alves Pereira

ivanioreumato@gmail.com

Izaias Pereira da Costa

izapec@hotmail.com

Javier Eduardo Rosa

javier.rosa@hospitalitaliano.org.ar

José Roberto Silva Miranda

jrsmiranda@hotmail.com

Julio Cesar Bertacini de Moraes

julio.moraes@hc.fm.usp.br

Manoel Barros Bertolo

manoelbb@fcm.unicamp.br

Manuel Buhl

manuelbuhl@hotmail.com

Maria Alícia Lázaro

dralazaro@icloud.com

Maria de Fátima Lobato C. da Sauma

fatimalobato@zipmail.com.br

Marcelo de Medeiros Pinheiro mpinheiro@uol.com.br

Monica Díaz

cleoni@bariloche.com.ar

Mônica Valéria Siqueira Santana de Vechi jvechi@uol.com.br

Osvaldo Luis Cerda

osvaldoluiscerda@gmail.com

Pablo Astesana

pabloastesana@yahoo.com.ar

Pablo Finucci Curi

pablofinu@hotmail.com

Paulo Louzada-Jr

plouzada@fmrp.usp.br

Reginaldo Botelho Teodoro reginaldobotelhot@gmail.com

Roberto Acayaba Toledo acayaba@famerp.com.br

Sílvia Papasidero sbpapasidero@yahoo.com.ar

Valeria Valim

val.valim@gmail.com 
Vander Fernandes

vf@uol.com.br

Veronica Saurit

vsaurit@gmail.com

Washington Alves Bianchi

wabianchi@yahoo.com.br

1 Hospital de Clinicas, Universidade Federal de Uberlândia, Uberlândia, Brazil

2 Uberlândia, Brazil

3 CEIM, Buenos Aires, Argentina

4 Faculdade de Medicina da Universidade Nove de Julho, São Paulo, Brazil

5 Sanatorio Güemes, Buenos Aires, Argentina

6 Hospital de Clínicas, Universidade Federal do Paraná, Curitiba, Brazil

7 Hospital das Clinicas da Universidade Federal de Minas Gerais, Belo Horizonte, Brazil IMIP, Recife, Brazil

9 Centro Platenses de reumatología, Buenos Aires, Argentina

10 Hospital César Milstein, Buenos Aires, Argentina

11 Centro Integral de Reumatología, Tucumán, Argentina

12 Clinica de Reumatologia, Osasco, Brazil

13 Atención Integral de reumatología, Buenos Aires, Argentina

14 Hospital de Clínicas Universidade Federal de Pernanbuco, Recife, Brazil

15 Hospital Evangélico, Curitiba, Brazil

16 Hospital Penna, Buenos Aires, Argentina

17 Hospital de Clínicas, Porto Alegre, Brazil

18 Sanatorio Adventista del Plata, Entre Ríos, Argentina

19 Hospital nacional de Clínicas, Córdoba, Argentina

20 Hospital Italiano, Buenos Aires, Argentina

21 Santa Casa Misericordia, Maceió, Brazil

22 Hospital Pedro Ernesto UERJ, Rio de Janeiro, Brazil

23 Hospital Governador Celso Ramos, Florianopolis, Brazil

24 Hospital de base, Brasília, Brazil

25 Sanatorio Parque, Córdoba, Argentina

26 Escola de Medicina, PUCRS, Porto Alegre, Brazil

27 Consultorio Petkovic, Mendoza, Argentina
Rogério de Melo Costa Pinto

rmcpinto@ufu.br

Miguel Angel Descalzo

descalzo.miguelangel@gmail.com

Juan Jesus Gomez-Reino

Juan.Jesus.Gomez-Reino.Carnota@sergas.es

28 Hospital Universitario da Universidade Federal de Santa Catarina, Florianopolis, Brazil

29 Hospital Universitario Universidade Federal de Mato Grosso do Sul, Campo Grande, Brazil

30 Artrocenter, Taubaté, Brazil

31 Hospital das Clinicas da Universidade de São Paulo, São Paulo, Brazil

32 Hospital de Clínicas UNICAMP, Campinas, Brazil

33 Instituto de Investigaciones Médicas Alfredo Lanari, Buenos Aires, Argentina

34 IARI, Buenos Aires, Argentina

35 Universidade do Pará, Belém, Brazil

36 Escola Paulista de Medicina Universidade Federal de São Paulo, São Paulo, Brazil

37 Clinica San Carlos de Bariloche, Bariloche, Río Negro, Argentina

38 Hospital Universidade Federal de Sergipe, Aracaju, Brazil

39 IREP, Buenos Aires, Argentina

40 Sanatorio Allende, Córdoba, Argentina

41 Centro Médico Mitre, Parana, Entre Ríos, Argentina

42 Faculdade de Medicina USP, Ribeirão Preto, Brazil

43 Hospital Universidade Federal Triânglo Mineiro, Uberaba, Brazil

44 Faculdade de Medicina, São José do Rio Preto, Brazil

45 Hospital Tornú, Buenos Aires, Argentina

46 Hospital Cassiano A Moraes Universidade Federal do Espirito Santo, Vitoria, Brazil

47 Hospital Geral, HGU, Cuiabá, Brazil

48 Hospital Privado, Córdoba, Argentina

49 Hospital Santa Casa Misericordia, Rio de Janeiro, Brazil

50 Faculdade de Matemática, Universidade Federal de Uberlândia, Uberlândia, Brazil

51 Research Unit, Fundacion piel sana AEDV, Madrid, Spain

52 Santiago University Clinical Hospital Institute of Medical Research, Santiago de Compostela, Spain 